\title{
Combining intensive practice nurse counselling or brief general practitioner advice with varenicline for smoking cessation in primary care: Study protocol of a pragmatic randomized controlled trial
}

Citation for published version (APA):

van Rossem, C., Spigt, M., Smit, E. S., Viechtbauer, W., Mijnheer, K. K., van Schayck, C. P., \& Kotz, D. (2015). Combining intensive practice nurse counselling or brief general practitioner advice with varenicline for smoking cessation in primary care: Study protocol of a pragmatic randomized controlled trial. Contemporary Clinical Trials, 41, 298-312. https://doi.org/10.1016/j.cct.2015.01.017

Document status and date:

Published: 01/01/2015

DOI:

10.1016/j.cct.2015.01.017

Document Version:

Publisher's PDF, also known as Version of record

\section{Document license:}

Taverne

\section{Please check the document version of this publication:}

- A submitted manuscript is the version of the article upon submission and before peer-review. There can be important differences between the submitted version and the official published version of record. People interested in the research are advised to contact the author for the final version of the publication, or visit the DOI to the publisher's website.

- The final author version and the galley proof are versions of the publication after peer review.

- The final published version features the final layout of the paper including the volume, issue and page numbers.

Link to publication

\footnotetext{
General rights rights.

- You may freely distribute the URL identifying the publication in the public portal. please follow below link for the End User Agreement:

www.umlib.nl/taverne-license

Take down policy

If you believe that this document breaches copyright please contact us at:

repository@maastrichtuniversity.nl

providing details and we will investigate your claim.
}

Copyright and moral rights for the publications made accessible in the public portal are retained by the authors and/or other copyright owners and it is a condition of accessing publications that users recognise and abide by the legal requirements associated with these

- Users may download and print one copy of any publication from the public portal for the purpose of private study or research.

- You may not further distribute the material or use it for any profit-making activity or commercial gain

If the publication is distributed under the terms of Article 25fa of the Dutch Copyright Act, indicated by the "Taverne" license above,

Download date: 26 Apr. 2023 


\title{
Combining intensive practice nurse counselling or brief general practitioner advice with varenicline for smoking cessation in primary care: Study protocol of a pragmatic randomized controlled trial
}

\author{
C. van Rossem ${ }^{\mathrm{a}, *}$, M. Spigt ${ }^{\mathrm{a}, \mathrm{b}}$, E.S. Smit ${ }^{\mathrm{c}, \mathrm{d}}$, W. Viechtbauer ${ }^{\mathrm{e}}$, K.K. Mijnheer ${ }^{\mathrm{f}}$, \\ C.P. van Schayck ${ }^{\mathrm{a}}$, D. Kotz ${ }^{\mathrm{a}}$ \\ ${ }^{a}$ CAPHRI School for Public Health and Primary Care, Department of Family Medicine, Maastricht University, Maastricht, The Netherlands \\ ${ }^{\mathrm{b}}$ General Practice Research Unit, Department of Community Medicine, The Arctic University of Norway, Tromsø, Norway \\ c CAPHRI School for Public Health and Primary Care, Department of Health Promotion, Maastricht University, Maastricht, The Netherlands \\ ${ }^{\mathrm{d}}$ Amsterdam School of Communication Research/ASCoR, Department of Communication Science, University of Amsterdam, Amsterdam, The Netherlands \\ e MHeNS School for Mental Health and Neuroscience, Department of Psychiatry and Psychology, Maastricht University, Maastricht, The Netherlands \\ ${ }_{\mathrm{f}}^{\mathrm{f}}$ Eindhoven Corporation of Primary Health Care Centres (SGE), Eindhoven, The Netherlands
}

\section{A R T I C L E I N F O}

\section{Article history:}

Received 18 August 2014

Received in revised form 23 January 2015

Accepted 24 January 2015

Available online 2 February 2015

\section{Keywords:}

Smoking cessation

Primary care

Brief advice

Intensive counselling

Practice nurse

Varenicline

Pragmatic design

\begin{abstract}
A B S T R A C T
Introduction: Combining behavioural support and pharmacotherapy is most effective for smoking cessation and recommended in clinical guidelines. Despite that smoking cessation assistance from the general practitioner can be effective, dissemination of clinical practice guidelines and efforts on upskilling has not lead to the routine provision of smoking cessation advice among general practitioners. Intensive counselling from the practice nurse could contribute to better smoking cessation rates in primary care. However, the effectiveness of intensive counselling from a practice nurse versus usual care from a general practitioner in combination with varenicline is still unknown.

Materials and methods: A pragmatic randomized controlled trial was conducted comparing: (a) intensive individual counselling delivered by a practice nurse and (b) brief advice delivered by a general practitioner; both groups received 12-weeks of open-label varenicline. A minimum of 272 adult daily smoking participants were recruited and treated in their routine primary care setting. The primary outcome was defined as prolonged abstinence from weeks 9 to 26 , biochemically validated by exhaled carbon monoxide. Data was analysed blinded according to the intention-to-treat principle and participants with missing data on their smoking status at followup were counted as smokers. Secondary outcomes included: one-year prolonged abstinence, short-term incremental cost-effectiveness, medication adherence, and baseline predictors of successful smoking cessation.

Discussion: This trial is the first to provide scientific evidence on the effectiveness, costeffectiveness, and potential mechanisms of action of intensive practice nurse counselling
\end{abstract}

Abbreviations: GP, general practitioner; PN, practice nurse; NRT, nicotine replacement therapy; SGE, Eindhoven Corporation of Primary Health Care Centres; CO, carbon monoxide; MI, Motivational Interviewing; MEMS ${ }$, Medication Event Monitoring System; ICER, incremental cost-effectiveness ratio; T0, baseline questionnaire; T9, questionnaire at 9 weeks' follow-up; T12, questionnaire at 12 weeks' follow-up; T26, questionnaire at 26 weeks' follow-up; T52, questionnaire at 52 weeks' follow-up; PRECIS, Pragmatic-Explanatory Continuum Indicator Summary.

* Corresponding author at: CAPHRI School for Public Health and Primary Care, Maastricht University, P.0. Box 616, 6200 MD Maastricht, The Netherlands. Tel.: + 31 43 3882202; fax: + 31433619344.

E-mail addresses: carolien.vanrossem@maastrichtuniversity.nl (C. van Rossem), m.spigt@maastrichtuniversity.nl (M. Spigt), e.S.smit@uva.nl (E.S. Smit), wolfgang.viechtbauer@maastrichtuniversity.nl (W. Viechtbauer), k.mijnheer@sge.nl (K.K. Mijnheer), o.vanschayck@maastrichtuniversity.nl (C.P. van Schayck), d.kotz@maastrichtuniversity.nl (D. Kotz). 
combined with varenicline under real-life conditions. This paper explains the methodology of the trial and discusses the pragmatic and/or explanatory design aspects.

Trial Registration: Dutch Trial Register NTR3067.

(c) 2015 Elsevier Inc. All rights reserved.

\section{Introduction}

Tobacco use is a prominent determinant of the global burden of disease and responsible for 31\% Disability Adjusted Life Years (DALY) lost [1]. In the Netherlands, still one out of four people are daily smokers [2]. Even though most smokers would like to quit [3], the number of quit attempts and their success rate is low [4]. Increase of smoking cessation can be achieved by improving the efficacy and effectiveness of smoking cessation treatments.

Primary care is in a strategic position to play an important role in smoking cessation: it has a wide reach into the population, it is easily accessible for smokers [5], it is a familiar environment and there is access to professional and effective help [6,7]. Smokers who are considered to be difficult to reach, e.g., smokers with a low social-economic status or psychological illnesses; heavy smokers; and smokers from different ethnic backgrounds, may be more easily reached in primary care. In countries were the primary care system is well developed, such as the Netherlands, around $80 \%$ of the smokers visit their primary healthcare centre each year [2].

Smoking cessation treatments available in primary care can be categorized into behavioural support and pharmacological aids. Behavioural support can be given within a continuum of care, from less intensive and one-time support (brief advice) to more intensive behavioural support with multiple sessions (counselling). There is a strong doseresponse relationship between number of sessions, total contact time, and abstinence showing that intensive counselling increases the chance of a successful quit attempt compared to less intensive support [8]. Effective pharmacological aids include nicotine replacement therapy (NRT), antidepressants bupropion and nortriptyline, and the partial nicotine receptor agonists varenicline and cytisine [9-11]. Varenicline had better quit rates in clinical trials compared to bupropion and NRT [12-14]. Combining behavioural support and pharmacotherapy is most promising and recommended in clinical guidelines [8,15-17].

The availability and effectiveness of multiple smoking cessation strategies from the general practitioner (GP) [6], dissemination of clinical practice guidelines, and efforts on upskilling, have not led to the routine provision of smoking cessation advice among GPs [18-20]. A survey in Australia found that GPs were very pessimistic about giving cessation advice, and only half of the GPs would give such advice in an ideal situation [20]. However, practice nurses (PNs), as an alternative workforce in primary care, have recently been introduced in the Netherlands with the aim to reduce the workload of GPs. They are expected to improve the quality of care by cost-effectively managing chronic illnesses and performing health promotion tasks such as smoking cessation [21]. Evidence for the effectiveness of PN smoking cessation counselling is limited, but results are positive and suggest the same effectiveness as the English Smoking Cessation Services [22]. Since PNs have more time for counselling than GPs, intensive counselling by the PN can contribute to higher smoking cessation rates in primary care.

Furthermore, a recent meta-analysis showed some evidence that the combination treatment increases smoking cessation success, but most studies used NRT [23]. Evidence on the effectiveness of combining counselling and varenicline is still limited and it could be that the effect of counselling is less evident when using varenicline, or that the effectiveness of varenicline is amplified by intensive counselling. Though, recent trials show promising results in favour of the combination of counselling and varenicline [24-26]. For example, when varenicline was combined with an intensive 240minute counselling program, more than half of the patients was prolonged abstinent at 6 months of follow-up, which was significantly better than the combination of placebo with the same intensive counselling program ( $58.1 \%$ vs $26.4 \%$, OR 3.87 , 95\% CI 2.11-7.11) [24]. Nonetheless, more support for the effect of combining varenicline with intensive versus less intensive counselling is needed. Moreover, reasons why the combination of intensive counselling and pharmacotherapy is most successful are still unknown. One of the underlying mechanisms to this effect might be that counselling increases adherence to medication, which finally leads to better quit rates [27]. Intensive counselling is also more expensive than brief advice and therefore the cost-effectiveness should be considered. Previous clinical trials were very explanatory using very strict in- and exclusion criteria, which limits the external validity of the outcomes. Also, most evidence on the effectiveness of varenicline resulted from research in clinical settings and not in real world primary care settings.

Therefore, there is a need for evaluating the effectiveness of intensive counselling from a PN versus usual care from a GP to provide healthcare professionals, policymakers, and insurance companies with evidence on the value of counselling from the PN and on the effectiveness of the combination treatment of intensive counselling by a PN with varenicline. When the PN is equally or more effective than the GP, smoking cessation could be shifted from the GP to the PN in order to reduce the workload of the GP and approach the preferences of the patient.

\section{Materials and methods}

\subsection{Objectives}

The primary objective was to compare the effectiveness of individual counselling by a PN combined with open-label varenicline versus brief advice by a GP combined with open label varenicline on biochemically validated prolonged abstinence from week 9 to week 26 after treatment initiation in smokers in a Dutch primary care setting.

Secondary objectives were:

- to determine the prolonged abstinence rate from weeks 9 to 52 ; 
- to investigate the short-term incremental cost-effectiveness from weeks 9 to 52 ;

- to investigate adherence to varenicline and whether adherence mediated the treatment effect of individual counselling by a PN on prolonged abstinence from weeks 9 to 26;

- to explore which participant characteristics at baseline are predictors of prolonged abstinence from weeks 9 to 26 (predictors independent of treatment assignment);

- to explore which participant subgroups are more likely to respond to intensive counselling by a PN (predictors dependent of treatment assignment).

\subsection{Design and setting}

The study was a pragmatic, parallel group, individually randomized controlled trial evaluating two behavioural support programmes combined with open-label varenicline for smoking cessation: usual care from a GP versus intensive counselling from a PN. For an overview of the study design, see Fig. 1.

The trial was conducted in the Eindhoven Corporation of Primary Health Care Centres (SGE) [28], which is a network of 10 primary healthcare centres covering approximately 65,000

Patient recruitment in SGE health care centres via GP, PN and leaflets.

\section{$\downarrow$}

Patients contacted the research team. Eligibility screening by telephone.

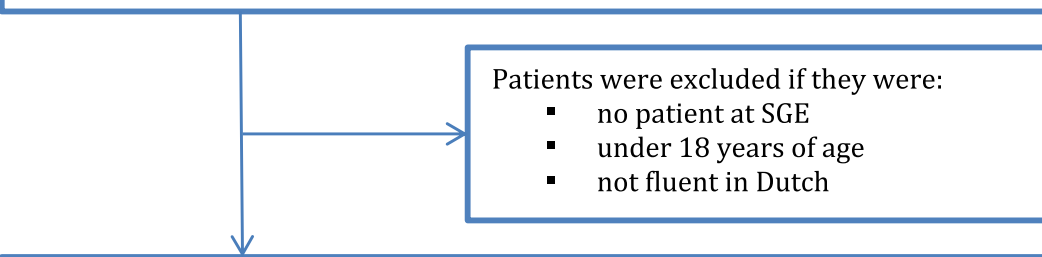

Patients received information letter + informed consent + baseline questionnaire.

Patients were excluded if they did not:

- complete the questionnaire

- returned the informed consent form

- get permission from their GP

Target enrollment $n=272$. Eligible participants were randomized into 2 groups, stratified by health care centre.

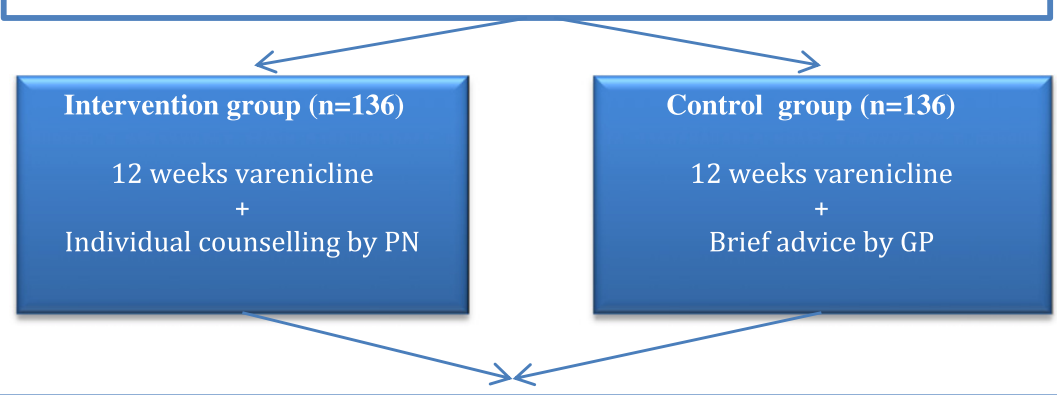

Follow-up at 9 weeks after start varenicline (CO measurement and questionnaire T9)

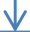

Follow-up measurement at 12 weeks after start varenicline (questionnaire T12)

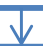

Follow-up at 26 weeks after start varenicline (CO measurement and questionnaire T26)

$\downarrow$

Follow-up at 52 weeks after start varenicline (CO measurement and questionnaire T52)

Fig. 1. Trial design. SGE = Eindhoven Corporation of Primary Health Care Centres, PN = practice nurse, GP = general practitioner, CO = carbon monoxide. 
patients in the Netherlands. In total 42 GPs and 13 PNs from SGE were actively involved in the recruitment and treatment of the trial participants. The logistics, including baseline and follow-up measurements, were covered by the research team of Maastricht University.

\subsection{Study population}

The aim was to recruit a study population that was a realistic reflection of smokers in primary care, since research volunteers and active treatment seekers may be unrepresentative for routine care $[29,30]$. Therefore, smokers who normally consulted their GP were recruited and as few exclusion criteria as possible were used. To recruit smokers who were motivated to quit smoking or at least willing to talk about smoking cessation within primary care, healthcare providers (GPs and PNs) and practice assistants were informed that smokers could be referred to the research team and leaflets entitled "Do you think about quitting?" were dispersed in the waiting rooms of the healthcare centres. The leaflet first discussed the benefits of smoking cessation, and then the trial was explained, describing it as an opportunity for smokers to quit. The costless prescription of pharmacotherapy was mentioned but not emphasized, so that this was not likely to be the main reason for participants to partake. The leaflets were printed on simple blue paper with black ink to save costs. Smokers aged 18 years or older and daily smokers at the time of randomization were included. There was no minimum limit for the number of cigarettes smoked per day. Many guidelines use a limit of 10 cigarettes per day or more for offering pharmacotherapy, mainly because pharmacological trials usually excludes smokers who smoke less $[8,15,16]$. However, it has been shown that the percentage "light" smokers (i.e., smoking less than 10 cigarettes per day) has been increasing over the last few years and currently constitutes of $29 \%$ of the smokers in the Netherlands [2]. Moreover, light smokers frequently use smoking cessation aids (about one in three) [31] and offering pharmacotherapy in this group of smokers is effective [32]. Smokers with contra-indications for the use of varenicline were excluded from the trial, as would happen in daily practice. The individual GP decided whether or not varenicline was prescribed to the individual participant.

\subsection{Intervention: intensive counselling by a practice nurse}

We decided to develop a context-specific treatment protocol based on existing, evidence-based methods and a pragmatic approach because: 1) there is no international consensus about which evidence-based strategies or techniques should be used, 2) interventions are often focused on motivating the smokers to quit and not at supporting a quit attempt, 3 ) the intervention used in Dutch primary care is too long (180 $\mathrm{min}$ ) [27] and gives no clear guidance what to do each consultation, 4) not all evidence about effective behaviour change strategies and techniques [33-35] has yet been translated into current counselling protocols and 5) practicebased experiences of healthcare providers and patients could make a protocol more transferable to real-life conditions.

The intervention was developed through a combination of a top-down and bottom-up approach. A top-down approach means that the intervention is based on a well- formed theory or literature findings (evidence-based approach), whereas a bottom-up approach means that practical experience drives the intervention development (pragmatic approach) [36]. A multidisciplinary advisory group was formed, consisting of three patients (smoker, ex-smoker, attempting ex-smoker) and three healthcare professionals from SGE (GP, PN, social psychiatric PN), three scientists and a policy maker from SGE. The goal was to develop a counselling protocol based on best practice and best evidence, which could be implemented as a small scale quality improvement in routine care. Working with the multidisciplinary team created a well-supported counselling protocol and commitment from healthcare professionals to engage in the trial.

\subsubsection{Timing of counselling sessions}

Participants from the intervention group were entitled to receive a total of $120 \mathrm{~min}$ of counselling. The protocol consisted of three individual face-to-face sessions and seven telephone sessions with a PN (see Table 1). We believed a $120 \mathrm{~min}$ counselling protocol would be feasible to implement in primary care and could be reimbursed by healthcare insurance companies in the Netherlands in the future. Only a smoking cessation intervention that is effective, feasible, and costeffective is likely to be adopted. The duration of the counselling sessions varied between 5 and $30 \mathrm{~min}$. We distinguished 4 phases in the counselling protocol: preparation phase (week 1 ), initial quitting phase (week 2), conscious quitting phase (weeks 3-5), and the maintenance phase (weeks 6-52) (see Table 1). The timing and duration of the sessions were based on relapse curves of aided and unaided quit attempts [12,13,37] and efficacy of front-loaded therapy [38]. While the original protocol included a first consultation with the GP for every participant, also for participants in the PN group, the healthcare providers within the multidisciplinary team decided to drop this regulation for practical reasons. Despite evidence suggests that treatment delivered by two types of clinicians (for example a GP and a PN) might be more effective than treatment delivered by only one type of clinician [39], the healthcare providers from the multidisciplinary team did not want to burden the GP with an extra consultation. Firstly, because this consultation was expected to be used solely for the prescription of varenicline. Secondly, because current practice also did not involve the GP for an extra consultation when the patient was treated by the PN. Therefore, participants in the intensive counselling group did not receive any assistance from their GP for smoking cessation.

\subsubsection{Effective elements of counselling protocol}

Effects of behaviour change interventions vary with the techniques used in the intervention $[34,35]$. The content of the current intervention was based on six behaviour change techniques, namely: (1) front-loaded therapy [38], (2) the use of expired carbon monoxide (CO) feedback [34,40], (3) stimulation of an ex-smoker identity [34,41,42], (4) stimulating adherence to varenicline [43], (5) use of a fixed target quit day [44,45], and (6) enhancing motivation and self-efficacy [34].

(1) Counselling was front-loaded which means that it started one week prior to the quit attempt and was most intensive in the first five weeks. (2) The use of CO feedback, prior to the quit attempt and 4 weeks after quitting should 
Table 1

Content and planning of the counselling protocol.

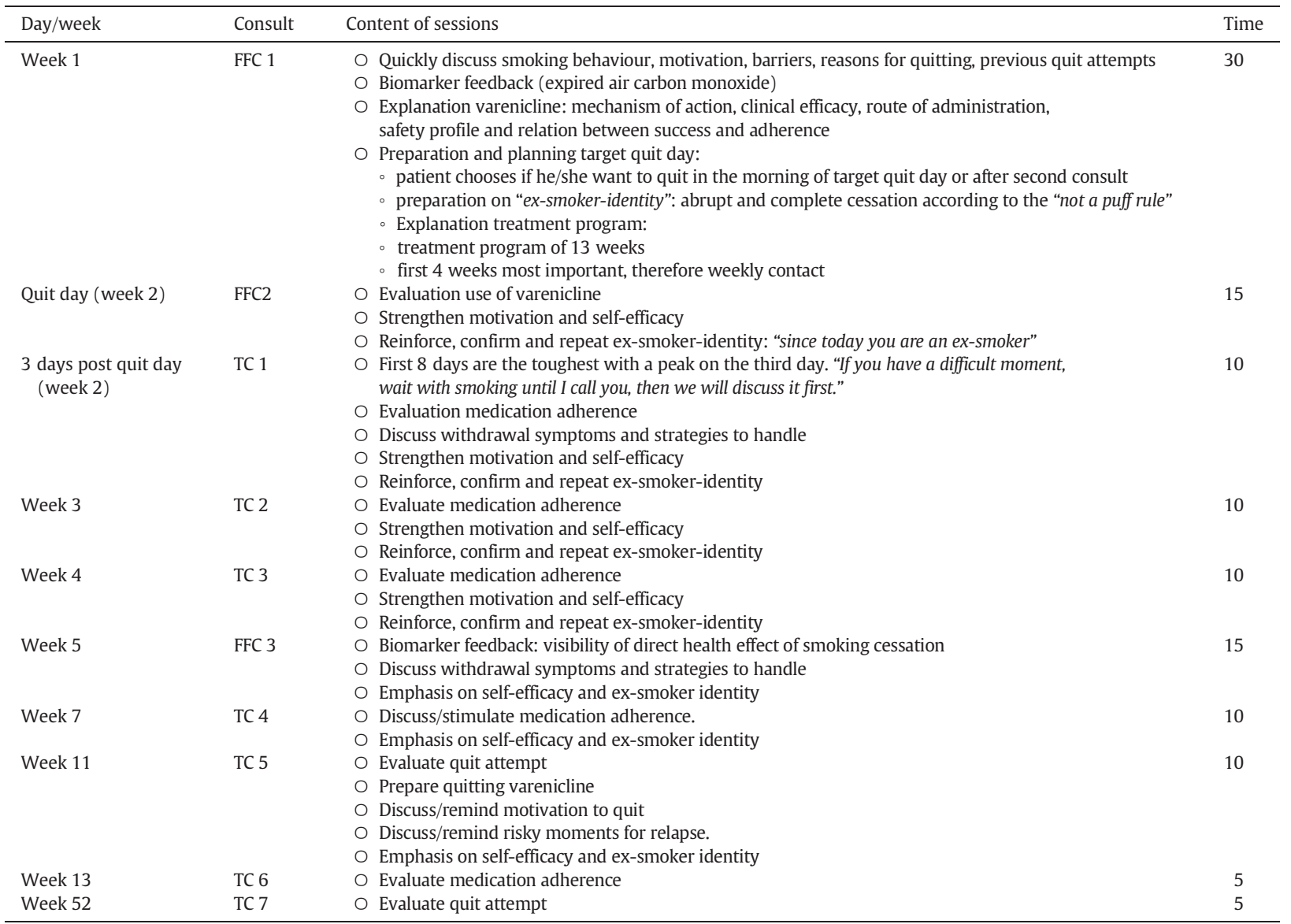

$\mathrm{FFC}=$ face-to-face consultation. $\mathrm{TC}=$ telephone consultation.

motivate smokers to continue quitting. With this technique, smokers were directly confronted with their lung intoxication and their risk on various diseases. After quitting, ex-smokers could see that their risk was immediately reduced. (3) Smokers were stimulated by the PN to adopt an ex-smoker identity by repeatedly using this term. This would help to remain abstinent through neurolinguistic programming. (4) Good adherence to varenicline doubles the quit rates, therefore adherence should be an important aspect during counselling [43]. The PN emphasized the need for good adherence and discussed factors related to poor adherence, e.g., experiencing side-effects and the conception that varenicline was not necessary anymore [46]. (5) The second session was planned on a fixed target quit date. The patient was allowed to choose prior to the appointment whether to quit smoking in the morning or after the second session. (6) The PN tried to strengthen the motivation and self-efficacy during every contact with the patient. They elaborated personal reasons to quit smoking from the patient, asked about and referred to situations where (prolonged) abstinence was difficult but successful, used verbal persuasion, and planned coping responses with the patient. An extensive description of the effective elements can be found in Table 1.

\subsubsection{Communication style}

Communication style can have a substantial impact on behaviour change [47]. Research on the style and quality of counselling or the effect of counselling training on cessation is scarce but increasing $[48,49]$. PNs participating in this trial were previously trained in the use of Dutch smoking cessation guidelines and Motivational Interviewing (MI). MI is a counselling style whereby the knowledge and experiences from the patient; eliciting and strengthening the intrinsic motivation of the patient; and resolving ambivalence towards change, play an important role. In contrast to more paternalistic and authoritarian counselling styles, the attitude with MI is more collaborative and supportive [50]. Also elements from cognitive behavioural therapy, e.g., elaborating cognitions and emotions with smoking cessation, identifying and removing environmental cues which trigger the urge to smoke were part of the PNs counselling style in routine care [51].

The emphasis of the counselling style was on strengthening motivation, self-efficacy, and enhancing a non-smoker-identity. We assumed that the participating PNs were capable of: 1) adopting a supportive and encouraging attitude; 2) communicating in a caring and patient way; 3 ) encouraging participants to talk about the quitting process; 4) identifying events, 
internal states, or activities that increase the risk of relapse; 5) teaching problem-solving skills to cope with high-risk situations for relapse; 6) identifying and challenging irrational beliefs about smoking; 7) considering indications and contraindications of smoking cessation medication (in particular varenicline); 8) creating realistic expectations of medication effects and alleviating fears regarding side effects and dependence potential;

\subsubsection{Implementation and adoption of the intervention}

The PNs only received a short, personal explanation of the counselling protocol by the researcher of approximately $1 \mathrm{~h}$, at the beginning of the trial. During the trial there was no monitoring to ensure adherence with the counselling protocol and PNs were free to deviate from the protocol when they believed this would benefit the participant. We were aware that this was insufficient to implement and control all elements of the counselling protocol perfectly. However, more instruction would have made the intervention more expensive and less pragmatic, while a real-world effectiveness trial is of substantial public health importance.

\subsection{Control: brief general practitioner advice}

The participants allocated to the control group received usual care from their GP. Smoking cessation interventions less than $3 \mathrm{~min}$ in duration have shown to be effective compared to no intervention (odds ratio (OR) 1.30, 95\% CI 1.10-1.60) [8]. Even among smokers who were not motivated to quit at a given time, $16 \%$ still made a quit attempt within six months after brief cessation advice [52]. Furthermore, smokers who received assistance in quitting from their GP were more satisfied with their quit attempt than those who did not $[53,54]$. Although some variations in practice exist, the control intervention minimally consisted of general advice to quit and a prescription for varenicline. Brief advice increases the chance of a successful quit attempt compared to no advice (risk ratio (RR) 1.66, 95\% confidence interval (CI) 1.42-1.94) [6]. Regularly, there was no quit date agreed and no follow-up visit arranged, but participants were free to contact their GP in case of questions or side-effects.

\subsection{Choice for varenicline}

The primary goal was to compare the effectiveness of two different forms of behavioural support when combined with pharmacotherapy. To eliminate one important source of confounding, the use of medication had to be standardised. Varenicline is a partial agonist and antagonist of the neuronal $\alpha_{4} \beta_{2}$ nicotinic acetylcholine receptor ( $\mathrm{nAChR}$ ), which is believed to have the highest specificity for nicotine [55-58] and was more effective than placebo for smoking cessation (RR 2.27, 95\% CI 2.02-2.55) [11]. Varenicline is more effective in reducing craving, withdrawal symptoms, and the reinforcing effects of smoking compared to bupropion and NRT, and generated better quit rates [12-14]. Varenicline has also shown to be the only pharmacological treatment for smoking cessation with proven long-term efficacy in smokers with Chronic Obstructive Pulmonary Disease (COPD) [59]. Furthermore, patients appeared to have less difficulties with taking varenicline, because this drug has been developed specifically for smoking cessation, in contrast to antidepressants as bupropion and nortriptyline [60].

\subsection{Use of varenicline}

Participants from both the intervention and control group received open-label varenicline to test its effectiveness under real life conditions. Varenicline was prescribed during an initial visit with the GP or PN in week 1. The use was initiated while the participant was still smoking and the target quit date was during the second week of treatment (see Table 1). The prescribed dosage was the recommended dosage of $0.5 \mathrm{mg}$ once a day for days $1-3,0.5 \mathrm{mg}$ twice a day for days 4-7, and then $1 \mathrm{mg}$ twice a day until the end of treatment (week 12). Nevertheless, healthcare professionals were free to deviate from this schedule when they believed this would be more appropriate for their participant. There was an interactive webbased program that is usually offered alongside the prescription of varenicline (www.liferewards.nl). Participants were allowed to visit this website.

\subsection{Outcomes}

\subsubsection{Primary outcome}

The primary outcome was biochemically validated prolonged abstinence from smoking from week 9 through week 26 after treatment initiation. A "grace period" was used from the target quit date in week 2 until week 9 (i.e., a period immediately after the target quit date in which continued smoking is not counted as a failure) [61]. A non-smoker was defined as a participant with a self-reported prolonged nonsmoking status with a maximum of 5 cigarettes smoked after the grace period, biochemically confirmed by exhaled $\mathrm{CO}$ in weeks 9 and 26 with a piCO + Smokerlyzer (Bedfont Scientific Ltd) as defined in the Russell Standard [61]. A CO-level of $<10$ ppm was used as a biomarker of abstinence [62]. Randomized participants who withdrew, were lost to followup, or failed to provide $\mathrm{CO}$ measurements for validation were classified as smokers.

\subsubsection{Abstinence from weeks 9 to 52}

The first secondary outcome was prolonged abstinence from smoking from week 9 through week 52 after treatment initiation. Successful one-year prolonged abstinence was defined as a participant with a self-reported prolonged nonsmoking status, with a maximum 5 cigarettes smoked after the grace period, biochemically confirmed by exhaled CO in weeks 9, 26, and 52 with a piCO + Smokerlyzer (Bedfont Scientific Ltd) as defined in the Russell Standard [61].

\subsubsection{Short-term incremental cost-effectiveness}

Economic evaluation studies aim to determine the costs and effects associated with an intervention in order to compare these results with other interventions or current practice [63] and to inform health policy. Calculating the costs per quitter is the primary method for economic evaluations in smoking cessation research [64]. However, due to the pragmatic design of the current study, a full cost-effectiveness analysis from a societal perspective was not possible and therefore a strippeddown procedure from a payer perspective was performed, excluding offset and societal costs [65]. 
Since one-year follow-up is the preferred time horizon for economic evaluations of smoking cessation interventions, the secondary outcome was used as the measure of effectiveness: biochemically validated prolonged abstinence from week 9 to week 52. Costs were based on direct intervention expenses and calculated from real resource use, accounting for professional time (consultations with healthcare professionals were registered into the electronic medical system (EMS) of SGE), and costs of varenicline (based on actual prescriptions from pharmacy fill records). The costs per quitter were computed for both groups and the short-term incremental costeffectiveness of the intervention group and the control group in comparison to each other were expressed as costs per extra quitter [65]. Evaluating the incremental cost-effectiveness ratio (ICER) enables to determine which of the two treatments offers most "value for money" in terms of enabling the largest number of smokers to quit at the lowest possible costs.

\subsubsection{Adherence to varenicline}

Medication intake was measured using electronic monitoring devices (Medication Event Monitoring System (MEMS $\left.{ }^{\circledR}\right)$ ). Also data from pharmacy fill records and questionnaire data were gathered. The starting dose for the first two weeks of varenicline was dispensed in the original packaging of the manufacturer $(11 \times 0.5 \mathrm{mg}, 14 \times 1 \mathrm{mg})$ by the pharmacy. From week 3, varenicline was dispensed in MEMS ${ }^{\circledR}$ vials by the pharmacy for a maximum of 4 weeks at a time. Participants had to refill their vial at the pharmacy until week 12 of treatment. The cap of these vials contained a microchip that saved the day and time of every opening ( $\geq 3 \mathrm{~s}$ ) by the participant during the 10 weeks of medication provision in the MEMS $®$ vials. It should be noted that the MEMS $₫$ vials did not prompt the participants to use their medication and participants were not stimulated by the research team to take the varenicline. The MEMS ${ }^{\circledR}$ data were read from an interface when the vial was returned to the pharmacy and transmitted into a computer using Powerview software (AARDEX Ltd.).

If patients do not use varenicline as prescribed, they do not benefit optimally from pharmacological support. Recently, it has been shown that good varenicline intake $(\geq 80 \%$ of days taken) was strongly associated with smoking cessation (6month abstinence rate $52 \%$ versus $25 \%$ ) [43]. Five outcome measures were used to assess adherence to varenicline in the current study: (1) daily adherence was the percentage of days on which any dose of medication was taken, (2) taking adherence was the percentage of prescribed doses taken, (3) dosing adherence was the percentage of correctly dosed days, (4) timing adherence was the percentage of inter-dose intervals not exceeding $25 \%$ of the prescribed dosing interval $(12 \mathrm{~h})$, and (5) persistence was the duration of medication intake in days with a maximum drug holiday of $72 \mathrm{~h}$.

\subsubsection{Baseline predictors of quit success}

Understanding the determinants of successful quitting is important to improve smoking cessation interventions. Several factors are known to predict whether a quit attempt is more or less likely to succeed, such as age, educational level, social gradient, nicotine dependence, number of cigaretess per day, age of smoking inititation, number and duration of previous quit attempts, intention to quit, confidence in succes in quitting, the presence of depression and/or anxiety, and urge to smoke [66-68]. The current trial included these and some unexplored, potentially interesting determinants, such as locus of control, type of smoker, and treatment preferences, which could complement the current knowledge on predictors of quit success.

\subsubsection{Treatment response}

Treatment response usually varies among individuals, and accounting for thatvariability in clinical study populations can be useful for translating clinical trial outcomes into recommendations for a more tailored treatment selection in routine care. In order to make responsible use of healthcare resources, identifying individual characteristics that moderate success in smoking cessation can help to match smokers with a strategy that is more likely to help them quit. For example, strategies could be tailored to personality traits [69], socio-demographic differences [70], smoking behaviour [2], or to initial response on treatment [71]. Unfortunately, few studies investigate differential response to smoking cessation interventions. One recent study from Rose et al. (2013) successfully adapted pharmacological treatment according to initial response to precessation nicotine patch use, which rescued smokers from an unsuccessful attempt [71]. The goal was to understand which participant subgroups are more likely to respond to intensive counselling from a PN.

\subsection{Questionnaires}

Questionnaires were sent at baseline (T0), at 9 weeks (T9), 12 weeks (T12), 26 weeks (T26) and 52 weeks (T52) (see Fig. 1). The following information was collected from each respondent: baseline demographic characteristics, self-reported health, past- and current smoking behaviour, nicotine dependence, smoking cessation treatment preferences, cigarette withdrawal symptoms, smoking-related cognitions, mental health, quality of life, life events, and therapeutic alliance. For a complete overview of the content of all questionnaires see Table 2. The questionnaires should be completed within 4 weeks after the targeted date.

\subsection{Adverse events}

Adverse (AEs) and serious adverse events (SAEs) reported spontaneously by the subject during telephone follow-up or observed by the researcher during CO-measurement were recorded. In questionnaire $\mathrm{T} 12$, participants were actively asked about the presence of adverse events. All possible adverse events of varenicline were listed with the response options "not at all", "very minor", "minor", "reasonable/ moderate", "strong", or "very strong" (see Table 3). Questionnaire T12 ("Did you experienced any other side effects that are not mentioned in the above questions?") and T26 ("Did you experienced side-effects after stopping varenicline or did any side-effects worsened after stopping varenicline?") also contained open-ended questions regarding adverse events.

\subsection{Sample size calculation}

The calculation of the required sample size was based on the difference in efficacy between the intervention and control group. Because studies comparing usual care from the GP with 
Table 2

Content of measurements per questionnaire.

\begin{tabular}{|c|c|c|c|c|c|}
\hline Concepts & T0 & T9 & $\mathrm{T} 12$ & $\mathrm{~T} 26$ & T52 \\
\hline Demographic characteristics & $\mathrm{X}$ & & & & \\
\hline Weight & $\mathrm{X}$ & $\mathrm{X}$ & $\mathrm{X}$ & $\mathrm{X}$ & $\mathrm{X}$ \\
\hline Lifestyle (breakfast, coffee, alcohol) & $\mathrm{X}$ & & & & \\
\hline Morbidity & $\mathrm{X}$ & & & & \\
\hline Health & $X$ & & & & $\mathrm{X}$ \\
\hline \multicolumn{6}{|l|}{ Smoking } \\
\hline Heaviness of Smoking Index (HSI) [72,73] & $\mathrm{X}$ & & & & \\
\hline Past and current smoking behaviour [74] & $\mathrm{X}$ & & & & \\
\hline Type of smoker & $\mathrm{X}$ & & & & \\
\hline Modified Cigarette Evaluation Questionnaire (mCEQ) [75] & $\mathrm{X}$ & $\mathrm{X}$ & $\mathrm{X}$ & $\mathrm{X}$ & \\
\hline Michigan Nicotine Reinforcement Questionnaire (MNRQ) [76] & $\mathrm{X}$ & $\mathrm{X}$ & $\mathrm{X}$ & $\mathrm{X}$ & $\mathrm{X}$ \\
\hline Modified Reasons for Smoking Scale (MRSS) [77] & $\mathrm{X}$ & & & & \\
\hline \multicolumn{6}{|l|}{ Quit smoking } \\
\hline Previous quit attempts [74] & $\mathrm{X}$ & & & & \\
\hline Smoking status [61] & & $\mathrm{X}$ & $\mathrm{X}$ & $\mathrm{X}$ & $\mathrm{X}$ \\
\hline \multicolumn{6}{|l|}{ Health perception } \\
\hline Health concerns [78] & $\mathrm{X}$ & & & & \\
\hline Risk perception [78] & $\mathrm{X}$ & & & & \\
\hline Self-exempting beliefs [78] & $\mathrm{X}$ & & & & \\
\hline \multicolumn{6}{|l|}{ Psychological constructs } \\
\hline Reasons For Quitting scale (RFQ) [79] & $\mathrm{X}$ & & & & \\
\hline Smoking Specific Locus of Control (SSLC) [80] & $\mathrm{X}$ & & & & \\
\hline Motivation to quit or maintain quitted & $\mathrm{X}$ & $\mathrm{X}$ & $\mathrm{X}$ & $\mathrm{X}$ & $\mathrm{X}$ \\
\hline Confidence in successful quitting & $\mathrm{X}$ & $\mathrm{X}$ & $\mathrm{X}$ & $\mathrm{X}$ & $\mathrm{X}$ \\
\hline Self-efficacy [74] & $\mathrm{X}$ & $\mathrm{X}$ & $\mathrm{X}$ & $\mathrm{X}$ & $\mathrm{X}$ \\
\hline Ex-smoker identity & & $\mathrm{X}$ & $\mathrm{X}$ & $\mathrm{X}$ & $\mathrm{X}$ \\
\hline \multicolumn{6}{|l|}{ Withdrawal and adverse effects } \\
\hline Minnesota Nicotine Withdrawal Scale (MNWS) [81-83] & $\mathrm{X}$ & $\mathrm{X}$ & $\mathrm{X}$ & $\mathrm{X}$ & $\mathrm{X}$ \\
\hline Urge to smoke [67] & $\mathrm{X}$ & $\mathrm{X}$ & $\mathrm{X}$ & $\mathrm{X}$ & $\mathrm{X}$ \\
\hline Adverse effects during use of varenicline & & & $\mathrm{X}$ & & \\
\hline Adverse effects after 6 months starting varenicline & & & & $\mathrm{X}$ & \\
\hline \multicolumn{6}{|l|}{ Treatment } \\
\hline Treatment preferences (GP versus practice nurse) & $\mathrm{X}$ & & & & \\
\hline Use of varenicline & & $\mathrm{X}$ & $\mathrm{X}$ & & \\
\hline Satisfaction with therapy & & $\mathrm{X}$ & & & \\
\hline Working Alliance Inventory Short-form (WAI-S) [84] & & $\mathrm{X}$ & & & \\
\hline Pharmacological treatment used other than varenicline & & $\mathrm{X}$ & & & \\
\hline Expectations regarding important success factors & $\mathrm{X}$ & & & & \\
\hline Expectations regarding varenicline $[85,86]$ & $\mathrm{X}$ & & & & \\
\hline \multicolumn{6}{|l|}{ Mental health } \\
\hline Hospital Anxiety and Depression Scale (HADS) [87-89] & $\mathrm{X}$ & $\mathrm{X}$ & $\mathrm{X}$ & $\mathrm{X}$ & $\mathrm{X}$ \\
\hline Life events (emotional major events in a person's life) & & & & $\mathrm{X}$ & \\
\hline Harm reduction (using less or alternative sources of nicotine) & & & & $\mathrm{X}$ & \\
\hline
\end{tabular}

T0 = questionnaire sent at baseline. T9 = questionnaire sent 9 weeks after starting varenicline. T12 = questionnaire sent 12 weeks after starting varenicline. T26 = questionnaire sent 26 weeks after starting varenicline. T52 = questionnaire sent 26 weeks after starting varenicline.

intensive counselling from the PN in combination with varenicline were unknown at the time of study planning, the estimated quit rates derived from the results of previous varenicline trials [12,13] and from one of our own smoking cessation trials that combined individual counselling with nortriptyline for smoking cessation [90]. The estimated quit rates of the control group were based on the quit rates when using varenicline only, since we expected that the assistance of the GP would consist of solitary the prescription of varenicline and would not add up to the effect of varenicline alone. Prolonged abstinence rates from weeks 9 to 26 were expected to be $35 \%$ in the intervention group and $20 \%$ in the control group. With $\alpha=0.05$ (two-sided), at least 136 participants needed to be included in each group to detect a clinically meaningful difference of $15 \%$ between the groups with an $80 \%$ chance. The total number of participants in the two groups should therefore be 272 . We did not add participants to correct for any participants who were lost-to-follow up, because those were regarded as smokers in the primary analysis. At this moment, study recruitment has been closed earlier than expected. In total, 295 participants were eligible for data analysis.

\subsection{Randomization}

Eligible smokers were randomly assigned in a 1:1 ratio to either the intervention group or control group by the use of a computer determined sequence, within an interactive web response system. After the patient was included in the trial, the research team contacted the healthcare centre, and the 
Table 3

Adverse events of varenicline examined in questionnaire T12.

\begin{tabular}{ll}
\hline Headache & Infection or inflammation of the airways \\
Dizziness & Weight gain \\
Increased fatigue & Increased appetite \\
Tensed muscles & Weight loss \\
Muscle twitching & Decreased appetite \\
Stiffness & Increased thirst \\
Muscle spasms & Dyspnoea \\
Paralysis & Cough \\
Chest pain & Sore throat \\
High blood pressure & Post nasal drip \\
Rash & Eye pain \\
Acne & Tinnitus \\
Sexual dysfunction & Difficulties falling asleep \\
Fever & Abnormal dreams \\
Nausea & Insomnia \\
Vomiting & Restlessness \\
Diarrhoea & Anxiety \\
Stomach ache & Panic reactions \\
Constipation & Depression \\
General discomfort & Suicidal thoughts \\
Hoarseness & \\
\hline
\end{tabular}

computer disclosed the allocation only one time during the telephone call. The health care centre contacted the patient to make an appointment with the healthcare professional of the group in which the patient was allocated. The member of the research team who was mostly involved with the randomization performed no CO-measurements and was not involved in data analysis. Randomization was stratified for healthcare centre, using a 6-block randomization scheme, to ensure a similar distribution of group intervention and control group among healthcare centres. No prognostic factors were used for balancing.

When two persons from the same family or close friends wanted to participate, they were paired and randomized as one cluster to the same group. This provided protection against contamination across study groups. No more than two persons per cluster were included in the trial.

Though the healthcare centre consisted of 10 locations, an individually randomized trial was chosen instead of a cluster randomized trial. A cluster randomized trial introduces a greater complexity in design, logistics, analysis and leads to a greater required sample size to preserve statistical power [91], since the area's in which the locations assumed dependence among individuals from the same location. To prevent and check for contamination, the participants were coded in their Electronic Medical Record (EMR) as a participant in the trial so that participants from the GP group would not be treated by the PN during the 6-month follow-up for smoking cessation. This was checked in the electronic database of SGE at the end of the trial.

\subsection{Blinding}

Blinding of participants and healthcare professionals was impossible due to the nature of the treatments. Outcome assessment was blinded for the researchers whenever possible. Researchers never directly asked about the treatment, disclosure by the participant during telephone and face-to-face contact was avoided as much as possible. Data analysis was fully blinded to group label (i.e., the data analyst was unaware of the meaning of the group labels) and participant identification number (i.e., participants received a new, random identification number during the analyses).

\subsection{Statistical analysis}

All tests were conducted with $\alpha=0.05$ (two-sided) and confidence intervals were based on a 95\% confidence level. All analyses were performed with SPSS (version 21; SPSS Inc, Chicago, Illinois).

\subsubsection{Primary analysis}

The primary analysis compared prolonged abstinence rates from weeks 9 to 26 among the two groups, with successful abstinence measured by the participants' self-reported prolonged non-smoking status and confirmed by an exhaled CO measurement below $10 \mathrm{ppm}$ in weeks 9 and 26. All randomized participants who received at least one dose of varenicline were included in an intention-to-treat analysis [92]. Participants with missing measurements (either due to intermittent missingness, dropout, or refusal to undergo a $\mathrm{CO}$ testing) were coded as smokers. To get an overall impression of the effectiveness, the proportion of abstinent participants was calculated for each measurement occasion and presented as a function of time for the two groups.

A multiple logistic regression model with a fixed effect for treatment group and a categorical variable corresponding to the healthcare centres was used to examine whether the chance of prolonged abstinence from weeks 9 to 26 differed significantly between the two groups (primary outcome analysis). The centre factor was included in the model to account for any absolute differences in success rates between centres and because the randomization was stratified by this variable $[93,94]$. An adjusted primary analyses was performed to correct for several, a priori chosen potential confounders measured at baseline: age, gender, socio-economic status, nicotine dependence, urge to smoke, self-efficacy, duration of longest quit attempt, depression, anxiety, share of smokers in the social environment, and alcohol misuse [66-68].

\subsubsection{Short-term incremental cost-effectiveness}

Costs per quitter (CPQ) were calculated for the intervention and control group, using the following formula: $\mathrm{CPQ}=(\mathrm{C} \times \mathrm{N})$ / $\mathrm{Q}$, where $\mathrm{C}$ were the direct costs of the treatment per smoker, $\mathrm{N}$ was the total number of participants randomized in the group, and Q was the total number of participants that achieved prolonged abstinence from week 9 to 52 [65]. Then an ICER was calculated using the cost of the intervention per quitter and intervention efficacy in means of additional life years gained, based on the direct method described by Stapleton and West (2012) [65]. This method is a conservative, simple, and clear way for estimating ICERs for several age groups. Estimates of life years gained were taken from the longest epidemiological study [95]. After discounting, the additional life years gained were adjusted for lifetime cessation without the intervention and relapse after final follow-up [65].

\subsubsection{Adherence to varenicline}

The association between treatment group and adherence was investigated, as well as the association between adherence and quit success. Reasons for non-adherence were compared between the intervention and control group and predictors for 
good adherence were investigated. Analysis of adherence to varenicline was based on returned MEMS ${ }^{\circledR}$ vials, pharmacy fill records and questionnaire data. For participants with missing data, an appropriate strategy for handling missing data was sought [96]. As compliance data are typically skewed, medication persistence and adherence were described by means, medians, and interquartile ranges.

Daily adherence, taking adherence, dosing adherence and timing adherence were compared across treatment groups by multiple linear regression analysis. In case the data showed the expected non-normal (skewed) distribution, the data was transformed. The models were adjusted for the following covariates: age, gender, educational level and heaviness of smoking index. An ancillary logistic regression analysis was performed after dichotomizing daily adherence into good adherence as $\geq 80 \%$ of days taken. To understand whether high intensity, individual counselling by a PN improves smoking cessation rates through higher medication adherence, a mediation analysis (a series of regression models) was performed [97]. Persistence was assessed using a Cox proportional hazard regression model to evaluate the risk of discontinuation across treatment groups, controlling for the same covariates as in the linear regression analysis. A Chisquare test was used to compare the reasons for stopping varenicline given by smokers and non-smokers with treatment group as predictor variable.

\subsubsection{Predictors of quitting success}

The following potential predictors measured at baseline were analysed in a multiple logistic regression model, controlled for treatment group: age (continuous), gender (dichotomous), socio-economic status (categorical), nicotine dependence (continuous), urge to smoke (continuous), self-efficacy (continuous), duration of longest quit attempt (continuous), the presence of anxiety and/or depression (continuous), share of smokers in the social environment (continuous), reinforcing effects of smoking (measured with the Michigan nicotine reinforcement questionnaire (MNRQ)) (2 domains, continuous), and alcohol misuse (categorical). Also, psychological functions of smoking (measured with the Modified Reasons of Smoking Scale (MRSS)) (4 domains, continuous) and locus of control (2 domains, continuous) were expected to predict quitting success and were included in the model.

\subsubsection{Treatment response}

Even though multiple factors potentially relate to heterogeneity of treatment response, due to insufficient power for the interaction test, the potential treat of multiple testing, and clinical usefulness, only three dichotomous predictors were explored [98]. These predictors were selected based on previous literature and clinical usefulness. Educational level (high vs. low), nicotine dependence (addicted vs. strongly addicted) and preferred treatment (yes vs. no; indicating whether the participant was assigned to the treatment s/he favoured (GP or PN)) were analysed in a logistic regression model with biochemically validated prolonged abstinence from weeks 9 to 26 as the outcome variable. Statistical significance values were presented from the change in the log-likelihood ratio on entering the interactions between the subgroup effects and the treatment effect into the model.

\subsection{Time frame}

Recruitment, inclusion and randomization of participants was planned to start in November 2011 and intended to continue for 18 months until April 2013. The last measurement of the primary outcome was expected in October 2013 and all secondary outcomes were expected to be collected in July 2014. The analysis of data regarding the primary research question was not initiated before the completion of follow-up and data collection in the last participants.

\subsection{Logistics}

An electronic, web-based Research Logistics Management System was used for data entry, review, and monitoring. The system provided a solid base for managing the personal data of the participants, as well as a randomization module for reliable distribution of the participants. The advantages of web-based data collection included the avoidance of an additional transcription step, fewer missing data, and the immediate availability of the data for cleaning and analysing. Electronic questionnaires allowed for easier tailoring of questions based on conditions and/or responses. Participants who were unable or unwilling to use the internet to fill out the questionnaires were provided with corresponding paper and pencil versions.

\subsection{Ethical approval and trial registration}

Ethical approval was obtained from the Medical Ethics Committee of Maastricht Academic Hospital and Maastricht University (NL30057.068.09/METC 09-03-075) and registered in the Dutch Trial Register (NTR3067).

\section{Discussion}

High quality evidence of the effectiveness of smoking cessation interventions is needed to inform health policy on smoking cessation in primary care. Primary care is in a strategic position to play an important role in smoking cessation [6,7] and has developed guidelines which contain successful strategies for smoking cessation [8,15-17]. According to these guidelines, combining behavioural support and pharmacotherapy is most successful. However, direct evidence on the effectiveness of combining counselling and varenicline is insufficient [24-26] and reasons for the combination being most successful are still unknown. Previous clinical trials were very explanatory and a real-life study directly investigating the effectiveness of intensive counselling in combination with varenicline was needed. Our primary objective was to compare the effectiveness of individual counselling by a PN with openlabel varenicline versus brief advice by a GP with open-label varenicline in smokers under real-life conditions in a primary care setting in the Netherlands. Secondary objectives included evaluating the cost-effectiveness and adherence to varenicline, and were aimed at better understanding the added value of intensive counselling.

This trial investigates the difference in effectiveness of brief advice (i.e., usual care) from a GP versus intensive counselling from a PN, and therefore not only considers a distinction between two different intensities of behavioural support, but also between two different types of healthcare providers. 


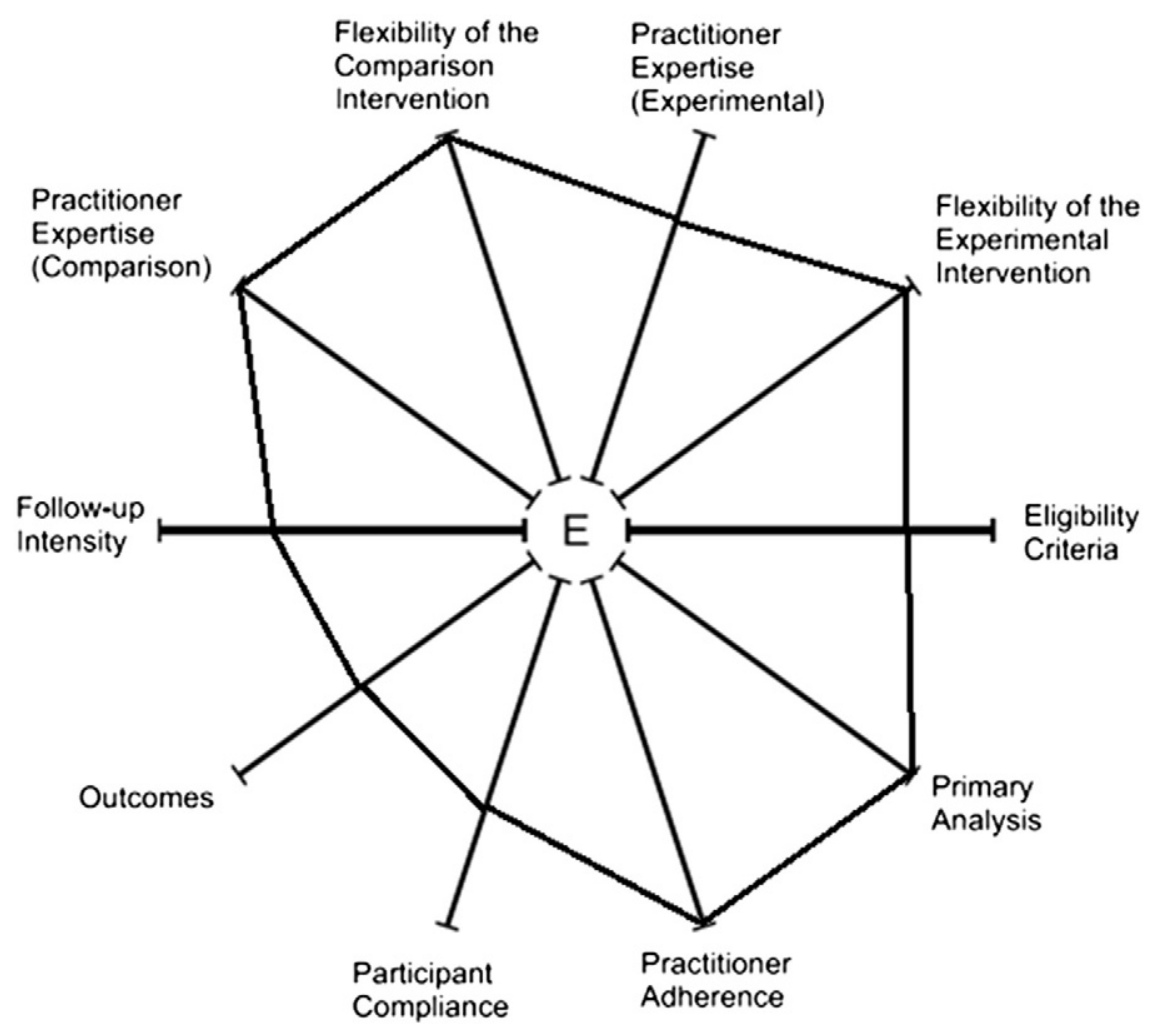

Fig. 2. PRECIS wheel. A visual representation of the ten indicators of the PRECIS tool. Each spoke represents one of the indicators, with the inside of the spoke representing a more explanatory judgement and the outside of the spoke representing a more pragmatic judgement.

Research shows not only a strong relationship between intensity of support (the number of contacts and the time spent during the contacts) and success rate [39], but also that behavioural smoking cessation interventions are more effective when delivered by a GP than when delivered by a nonphysician healthcare professional, such as a PN [39]. A recent study confirmed that even brief cessation advice from a GP can be powerful [52]; no such evidence is available for other healthcare professionals. Conversely, literature suggests that in the Netherlands only less than a quarter of all smokers who consult their GP actually receive brief cessation advice [2]. Moreover, smokers prefer assistance from the PN since the GP is very passive in smoking cessation, and a PN has more time for assistance and for offering a more tailored approach $[99,100]$. We expected that usual care from the GP consisted of only a single consultation wherein varenicline was prescribed and that there was no guidance at all. Therefore, we supposed that the effect of 120 min of counselling from the PN would outweigh the effect of 10 min of counselling from the GP.

The main strength of this trial was the pragmatic design, improving the generalizability of the results. However, certain concessions to the real-life situation were made to improve the internal validity of the trial. To assess whether elements of the trial could be identified as being more pragmatic or explanatory, we used the Pragmatic-Explanatory Continuum Indicator Summary (PRECIS) tool [101]. In general, pragmatic trials investigate whether the intervention works under usual conditions, whereas explanatory trials look at the effectiveness under ideal conditions [101]. The PRECIS tool provides a visual representation over ten research domains and shows that the current trial is largely pragmatic (see Fig. 2). Some decisions made the trial less pragmatic (see Table 4). For example: the primary outcome (domain 7), prolonged smoking cessation, was measured using a telephonic questionnaire and if the participant claimed to be a non-smoker an appointment for a CO-measurement was made with the research team. It would have been more pragmatic if the registration of self-reported smoking status was handled by the health centres as they would normally do. However, this would have led to bias since PNs are probably more accurate in collecting smoking status then GPs and the time of registering smoking status may differ among participants. Furthermore, the smoking status needed to be biochemically validated and measured in an identical way in both research groups.

The trial had some potential limitations. The primary outcome of smoking cessation trials is preferably measured after 52 weeks of follow-up, but his would have required a much larger sample size. Nonetheless, the prolonged abstinence rate from weeks 9 to 26 , as in the current trial, is a good approximation for the abstinence rate from weeks 9 to 52 . Furthermore, the use of intention-to-treat (ITT) is conservative, however it needs to be mentioned that due to the pragmatic design, there is a chance of post-randomization exclusion. Potential participants were not physically seen by the research team or healthcare professionals before randomization to check their study eligibility. Therefore, it could happen that 
Table 4

Explanation of the different domains of the Pragmatic-Explanatory Continuum Indicator Summary for scoring.

Domain 1: Participant eligibility

Participants who smoked, regardless of their motivation to stop smoking or responsiveness to previous treatment, could have participated in the trial. As few as possible exclusion criteria were used. Participants had to be over 18 years and had no known contra-indications for the use of varenicline, which was already routinely applied in primary care. Also participants had to be sufficiently proficient in Dutch, which could lead to selection bias and exclude a group of ethnic minorities in the Netherlands. However, no figures were known about how many of those ethnic minorities are not fluent in Dutch, smoke and seek treatment in primary care. Nonetheless, ethnic minorities are often part of more deprived socioeconomic groups. Previous studies showed that lower educated patients were more likely to be smokers and smoked more cigarettes per day [102], and that deprived socioeconomic groups had the same or higher initiation ratios, were just as likely to use pharmacological aids for quitting, but had lower quitting success compared with patient in higher socioeconomic groups [70,102].

When patients wanted to participate in the trial, they had to contact a telephone number or send an e-mail to the research team. Then, before randomization, participants were obliged to fill in the baseline questionnaire completely, which took about 30 min. This could have led to the inclusion of participants who were more motivated to participate in research, but in practice, none of the participants stepped out because of the questionnaire.

Domain 2: Intervention condition: flexibility

Though a new protocol was developed for the intensive counselling, the PNs were highly flexible on how to apply the counselling. The protocol was used as best-practice and best-evidence, but there was the possibility to give more or less sessions if needed.

Domain 3: Intervention condition: healthcare providers expertise

Similar to primary care practices elsewhere in the Netherlands, SGE employed PNs who were capable of delivering individual counselling to smokers. All nurses were trained in giving smoking cessation assistance as this is mandated by health insurers to get reimbursement. This training consisted of at least 2 days of training and included information on the behavioural and physiological reasons for smoking, the stages of change, increasing motivation, preparation and assistance on the target quit day, aftercare, possible withdrawal symptoms, pharmacological options and possible self-help materials. Most PNs also did a short Motivational Interviewing course of at least one day. Though information about training of the average Dutch PN is unknown, we believed the PNs from SGE were generalizable with PNs in the rest of the Netherlands.

The PNs were not additionally trained in the context of the trial. The PNs only received a short, personal explanation of the counselling protocol by the researcher of approximately one hour, at the beginning of the trial. During the trial there was no monitoring to check for treatment fidelity and ensure adherence with the counselling protocol and PNs were free to deviate from the content and planning of the protocol when they believed this would benefit the participant. The PNs had been trained according to the Dutch guidelines for smoking cessation and had received training 2-3 years before the start of the trial. Therefore we assumed that the PNs were capable of giving smoking cessation support at a level that can be considered representative for the average PN in the Netherlands.

Domain 4: Control condition: flexibility

GPs were asked to give care as usual and were free to organize the support as they wanted if no PN existed. GPs needed at least one face-to-face contact in order to prescribe varenicline, which was already applied in routine care. By all means, referral to the PN was not allowed.

Domain 5: Control condition: healthcare providers expertise

GPs were not additionally trained in smoking cessation and gave smoking cessation assistance as usual. Although there are some variations in practice, usual care typically consisted of general advice to quit (sometimes with setting a quit date) and a prescription for varenicline.

Domain 6: Follow-up intensity

Contact for follow-up, including a quick telephone call to verify the participants' smoking status, a questionnaire and possibly a carbon monoxide measurement, took place at week 9, week 12, week 26 and week 52. Since the first five weeks seemed most important in prolonged smoking cessation, the participants did not have contact with the research team during this sensitive period. The first contact was after 9 weeks, and during all contacts, the researcher was not allowed to give any advice regarding smoking cessation or enter into a personal relationship with the participant.

Domain 7: Primary trial outcome

The primary outcome was prolonged smoking cessation, which was also a relevant outcome for participants and healthcare providers. Prolonged smoking cessation was measured by combining self-report during a telephone call and a carbon monoxide measurement using a handheld monitor when the participant claimed to be a non-smoker. These measurements were quick, convenient, quantitative, and did not require invasive procedures. However, contact with the research team was necessary to obtain those data for both groups.

Domain 8: Participant compliance with the intervention (medication and treatment)

Participants' adherence to varenicline was monitored using electronic monitoring devices (Medication Event Monitoring System (MEMS $\left.{ }^{2}\right)$. Though participants did not receive any feedback on how they took their medication and were told that the information was used to associate the time of intake with adverse events, it is not unlikely that the use of such a system influenced participants' awareness to medication adherence.

Domain 9: Healthcare provider compliance with the intervention

There was no measurement of practitioner adherence to improve treatment outcomes. However, GPs and PNs were accounting for professional time by registering the consultations into the electronic database. GPs registered one single or double consultation per session PNs registered a code which represented the time spent on the consultation $(5,10,15$ and $30 \mathrm{~min})$. Though the use of this code was implemented during the start of the trial, SGE needed this information for own use as well.

Domain 10: Analysis of primary outcome

We used an intention-to-treat analysis. If participants were eligible for participating, filled in the baseline questionnaire and received at least one dose of varenicline, they were accepted for analysis. The analysis included all participants in the group they were allocated, regardless of eligibility, compliance with treatment, or adherence to varenicline. In other words, the analysis attempted to see whether the treatment worked under the usual conditions, with all the noise inherent therein.

due to improper inclusion, patients were excluded postrandomization if they did not meet the eligibility criteria. Another limitation was that only patients and healthcare professionals from SGE were included in the trial. However, the participating health centres were assumed to be representative for other healthcare centres in the Netherlands regarding 
their size, policy, and patient characteristics. Also, GPs were not specially trained in supporting smoking cessation and the PNs were not more trained then mandated by health insurers. Therefore, the results of the trial should be generalizable for the Dutch situation (see also domains 1, 3, and 5 in Table 4). Furthermore, no methods to check for treatment fidelity were incorporated in the protocol, which makes it difficult to judge the content of the consultations between participants and GP/PN. However, we believe that both types of healthcare providers were competent in giving smoking cessation assistance as one might expect from the training they had received. Nonetheless, we did an alternative quantitative check on the number of consultations and time spent on counselling in the trial based on the registrations in the electronic medical system (EMS) for each participant.

In the future, it is likely that an important portion of smoking cessation support will be delivered in primary care by GPs and PNs. Evaluation of the effectiveness and cost-effectiveness of both professions is essential to inform the discussion about how to effectively structure smoking cessation in primary care. Furthermore, empirical evidence to encourage a combination treatment of behavioural therapy and varenicline is needed. Therefore, the results of this trial will make an important contribution to the knowledge on this subject. Additionally, more research is desired in what mediates the mechanisms of change in the intervention. Not only the quantity of counselling seems important in improving quit rates, but also the quality of counselling. Questions about what is good counselling and how this influences quit success should be investigated in the future.

\section{Acknowledgements}

The authors would like to thank all participating patients and healthcare providers from SGE to make this trial possible. The authors would also like to express their gratitude towards the members of the multidisciplinary advisory group for their enthusiasm, input and encouragement.

This was an investigator-initiated trial and funded by a collaboration of Eindhoven Corporation of Primary Health Care Centres (SGE), Pfizer (grant number GPIHP_RG_2010014T1330) and Caphri. SGE had no involvement in the data collection, analysis and interpretation of data. Pfizer had no involvement in the study design, data collection, analysis and interpretation of data, in the writing of the report nor the decision to submit the article. Pfizer supplied the varenicline during the trial.

\section{References}

[1] Lim SS, Vos T, Flaxman AD, Danaei G, Shibuya K, Adair-Rohani H, et al. A comparative risk assessment of burden of disease and injury attributable to 67 risk factors and risk factor clusters in 21 regions, 1990-2010: a systematic analysis for the Global Burden of Disease Study 2010. Lancet 2013;380(9859):2224-60.

[2] Kotz D, Willemsen MC, Brown J, West R. Light smokers are less likely to receive advice to quit from their GP than moderate-to-heavy smokers: a comparison of national survey data from the Netherlands and England. Eur J Gen Pract 2013;19(2):99-105.

[3] Smit ES, Fidler JA, West R. The role of desire, duty and intention in predicting attempts to quit smoking. Addiction 2011;106(4):844-51.

[4] Zhu SH, Lee M, Zhuang YL, Gamst A, Wolfson T. Interventions to increase smoking cessation at the population level: how much progress has been made in the last two decades? Tob Control 2012;21(2):110-8.

[5] Zwar NA, Richmond RL. Role of the general practitioner in smoking cessation. Drug Alcohol Rev 2006;25(1):21-6.
[6] Stead L, Bergson G, Lancaster T. Physician advice for smoking cessation. Cochrane Database Syst Rev 2008(2):Cd000165.

[7] Rice VH, Stead LF. Nursing interventions for smoking cessation. Cochrane Database Syst Rev 2008(1):Cd001188

[8] Fiore MC, Jean CR, Baker TB, Bailey WC, Benowitz NL, Curry SJ, et al. Treating Tobacco Use and Dependence: 2008 Update. Washington D.C.: U.S. Department of Health and Human Services; 2008

[9] Stead LF, Perera R, Bullen C, Mant D, Hartmann-Boyce J, Cahill K, et al. Nicotine replacement therapy for smoking cessation. Cochrane Database Syst Rev 2012;11:CD000146.

[10] Hughes JR, Stead LF, Lancaster T. Antidepressants for smoking cessation. Cochrane Database Syst Rev 2007(1):Cd000031.

[11] Cahill K, Stead LF, Lancaster T. Nicotine receptor partial agonists for smoking cessation. Cochrane Database Syst Rev 2012;4:Cd006103.

[12] Gonzales D, Rennard SI, Nides M, Oncken C, Azoulay S, Billing CB, et al. Varenicline, an alpha4beta2 nicotinic acetylcholine receptor partial agonist, vs sustained-release bupropion and placebo for smoking cessation: a randomized controlled trial. JAMA 2006;296(1):47-55.

[13] Jorenby DE, Hays JT, Rigotti NA, Azoulay S, Watsky EJ, Williams KE, et al. Efficacy of varenicline, an alpha4beta2 nicotinic acetylcholine receptor partial agonist, vs placebo or sustained-release bupropion for smoking cessation: a randomized controlled trial. JAMA 2006; 296(1):56-63.

[14] Aubin HJ, Bobak A, Britton JR, Oncken C, Billing Jr CB, Gong J, et al. Varenicline versus transdermal nicotine patch for smoking cessation: results from a randomised open-label trial. Thorax 2008;63(8): 717-24.

[15] Partnership on smoking cessation. Guideline treatment of tobacco dependence. The Hague: Partnership on smoking cessation; 2009.

[16] Chavannes NH, Kaper J, Frijling BD, Van der Laan JR, Jansen PWM, Geurroij S, et al. Practice guideline 'smoking cessation' from the dutch college of general practitioners. Huisarts Wet 2007;50(7):306-14.

[17] National Institute for Health and Clinical Excellence. NICE public health guidance 10: smoking cessation services. Manchester: National Institute for Health and Clinical Excellence; 2008.

[18] De Korte D, Nagelhout G, Willemsen MC. Theme publication: advice on smoking cessation by general practitioner in the Netherlands 20012009. The Hague: Stivoro - for a smoke free future; 2010

[19] West R, DiMarino ME, Gitchell J, McNeill A. Impact of UK policy initiatives on use of medicines to aid smoking cessation. Tob Control 2005;14(3): 166-71.

[20] Young JM, Ward JE. Implementing guidelines for smoking cessation advice in Australian general practice: opinions, current practices, readiness to change and perceived barriers. Fam Pract 2001;18(1):14-20.

[21] Kotz D, Wagena EJ, Wesseling G. Smoking cessation practices of Dutch general practitioners, cardiologists, and lung physicians. Respir Med 2007; 101(3):568-73.

[22] Zwar NA, Richmond RL, Forlonge G, Hasan I. Feasibility and effectiveness of nurse-delivered smoking cessation counselling combined with nicotine replacement in Australian general practice. Drug Alcohol Rev 2011;30(6):583-8.

[23] Stead LF, Lancaster T. Behavioural interventions as adjuncts to pharmacotherapy for smoking cessation. Cochrane Database Syst Rev 2012;12: CD009670.

[24] Cinciripini PM, Robinson JD, Karam-Hage M, Minnix JA, Lam C, Versace F, et al. Effects of varenicline and bupropion sustained-release use plus intensive smoking cessation counseling on prolonged abstinence from smoking and on depression, negative affect, and other symptoms of nicotine withdrawal. JAMA Psychiatry 2013;70(5):522-33.

[25] Swan GE, McClure JB, Jack LM, Zbikowski SM, Javitz HS, Catz SL, et al. Behavioral counseling and varenicline treatment for smoking cessation. Am J Prev Med 2010:38(5):482-90.

[26] Smith BJ, Carson KV, Brinn MP, Labiszewski NA, Peters MJ, Fitridge R, et al. Smoking Termination Opportunity for inPatients (STOP): superiority of a course of varenicline tartrate plus counselling over counselling alone for smoking cessation: a 12-month randomised controlled trial for inpatients. Thorax 2013;68(5):485-6.

[27] Christenhusz LC, Prenger R, Pieterse ME, Seydel ER, van der Palen J. Costeffectiveness of an intensive smoking cessation intervention for COPD outpatients. Nicotine Tob Res 2012;14(6):657-63.

[28] Website Stichting Gezondheidscentra Eindhoven. www.sge.nl.

[29] Hughes JR, Giovino GA, Klevens RM, Fiore MC. Assessing the generalizability of smoking studies. Addiction 1997;92(4):469-72.

[30] Gilbert H, Sutton S, Sutherland G. Who calls QUIT? The characteristics of smokers seeking advice via a telephone helpline compared with smokers attending a clinic and those in the general population. Public Health 2005;119(10):933-9.

[31] Kotz D, Fidler J, West R. Very low rate and light smokers: smoking patterns and cessation-related behaviour in England, 2006-11. Addiction 2012;107(5):995-1002. 
[32] Baha MY, Le Faou AL. Smoking cessation interventions offered to French adult light smokers: a heterogeneous population with specific needs. Eur Addict Res 2010;16(3):162-9.

[33] Abraham C, Michie S. A taxonomy of behavior change techniques used in interventions. Health Psychol 2008;27(3):379-87.

[34] West R, Walia A, Hyder N, Shahab L, Michie S. Behavior change techniques used by the English Stop Smoking Services and their associations with short-term quit outcomes. Nicotine Tob Res 2010; 12(7):742-7.

[35] van Achterberg T, Huisman-de Waal GG, Ketelaar NA, Oostendorp RA, Jacobs JE, Wollersheim HC. How to promote healthy behaviours in patients? An overview of evidence for behaviour change techniques. Health Promot Int 2011;26(2):148-62.

[36] Vansteenkiste M, Williams GC, Resnicow K. Toward systematic integration between self-determination theory and motivational interviewing as examples of top-down and bottom-up intervention development: autonomy or volition as a fundamental theoretical principle. Int J Behav Nutr Phys Act 2012;9:23.

[37] Hughes JR, Keely J, Naud S. Shape of the relapse curve and longterm abstinence among untreated smokers. Addiction 2004;99(1): 29-38.

[38] Garvey AJ, Kalman D, Hoskinson Jr RA, Kinnunen T, Wadler BM, Thomson CC, et al. Front-loaded versus weekly counseling for treatment of tobacco addiction. Nicotine Tob Res 2012;14(5):578-85.

[39] Fiore MC, Jaén C, Baker TB, Bailey WC, Benowitz NL, Curry SJ, et al. Treating tobacco use and dependence: 2008 update U.S. Public Health Service Clinical Practice Guideline executive summary. Respir Care 2008; 53(9):1217-22

[40] Shahab L, West R, McNeill A. A randomized, controlled trial of adding expired carbon monoxide feedback to brief stop smoking advice: evaluation of cognitive and behavioral effects. Health Psychol 2011; 30(1):49-57.

[41] Vangeli E, West R. Transition towards a 'non-smoker' identity following smoking cessation: an interpretative phenomenological analysis. $\mathrm{Br} \mathrm{J}$ Health Psychol 2012;17(1):171-84.

[42] Tombor I, Shahab L, Brown J, West R. Positive smoker identity as a barrier to quitting smoking: findings from a national survey of smokers in England. Drug Alcohol Depend 2013;133(2):740-5.

[43] Catz SL, Jack LM, McClure JB, Javitz HS, Deprey M, Zbikowski SM, et al. Adherence to Varenicline in the COMPASS Smoking Cessation Intervention Trial. Nicotine Tob Res 2011;13(5):361-8.

[44] Hughes JR, Russ CI, Arteaga CE, Rennard SI. Efficacy of a flexible quit date versus an a priori quit date approach to smoking cessation: a cross-study analysis. Addict Behav 2011;36(12):1288-91.

[45] Rennard S, Hughes J, Cinciripini PM, Kralikova E, Raupach T, Arteaga C, et al. A randomized placebo-controlled trial of varenicline for smoking cessation allowing flexible quit dates. Nicotine Tob Res 2012;14(3): 343-50.

[46] Balmford J, Borland R, Hammond D, Cummings KM. Adherence to and reasons for premature discontinuation from stop-smoking medications: data from the ITC Four-Country Survey. Nicotine Tob Res 2011;13(2): 94-102.

[47] Miller WR, Rose GS. Toward a theory of motivational interviewing. Am Psychol 2009;64(6):527-37.

[48] Michie S, Churchill S, West R. Identifying evidence-based competences required to deliver behavioural support for smoking cessation. Ann Behav Med 2011;41(1):59-70.

[49] Carson KV, Verbiest ME, Crone MR, Brinn MP, Esterman AJ, Assendelft WJ, et al. Training health professionals in smoking cessation. Cochrane Database Syst Rev 2012;5:CD000214.

[50] Miller WR, Rollnick S. Motivational interviewing: preparing people to change. 3rd ed. New York, NY: The Guilford Press; 2002.

[51] Hofmann SG. An introduction to modern CBT. Psychological solutions to mental health problems. Chichester, UK: Wiley-Blackwell; 2011.

[52] Kotz D, Brown J, West R. Predictive validity of the Motivation To Stop Scale (MTSS): a single-item measure of motivation to stop smoking. Drug Alcohol Depend 2013;128(1-2):15-9.

[53] Solberg LI, Boyle RG, Davidson G, Magnan SJ, Carlson CL. Patient satisfaction and discussion of smoking cessation during clinical visits. Mayo Clin Proc 2001;76(2):138-43.

[54] Quinn VP, Stevens VJ, Hollis JF, Rigotti NA, Solberg LI, Gordon N, et al. Tobacco-cessation services and patient satisfaction in nine nonprofit HMOs. Am J Prev Med 2005;29(2):77-84

[55] Coe JW, Brooks PR, Vetelino MG, Wirtz MC, Arnold EP, Huang J, et al. Varenicline: an alpha4beta2 nicotinic receptor partial agonist for smoking cessation. J Med Chem 2005;48(10):3474-7.

[56] Rollema H, Chambers LK, Coe JW, Glowa J, Hurst RS, Lebel LA, et al. Pharmacological profile of the alpha4beta2 nicotinic acetylcholine receptor partial agonist varenicline, an effective smoking cessation aid. Neuropharmacology 2007;52(3):985-94.
[57] Benowitz NL, Porchet H, Jacob III P. Nicotine dependence and tolerance in man: pharmacokinetic and pharmacodynamic investigations. Prog Brain Res 1989;79:279-87.

[58] Fenster CP, Rains MF, Noerager B, Quick MW, Lester RA. Influence of subunit composition on desensitization of neuronal acetylcholine receptors at low concentrations of nicotine. J Neurosci 1997;17(15):5747-59.

[59] Tashkin DP, Rennard S, Hays JT, Ma W, Lawrence D, Lee TC. Effects of varenicline on smoking cessation in patients with mild to moderate COPD: a randomized controlled trial. Chest 2010;139(3):591-9.

[60] Etter JF, Schneider NG. An internet survey of use, opinions and preferences for smoking cessation medications: nicotine, varenicline, and bupropion. Nicotine Tob Res 2013;15(1):59-68.

[61] West R, Hajek P, Stead L, Stapleton J. Outcome criteria in smoking cessation trials: proposal for a common standard. Addiction 2005; 100(3):299-303.

[62] Christenhusz L, de Jongh F, van der Valk P, Pieterse M, Seydel E, van der Palen J. Comparison of three carbon monoxide monitors for determination of smoking status in smokers and nonsmokers with and without COPD. J Aerosol Med 2007;20(4):475-83.

[63] Drummond MF, Sculpher MJ, Torrance G, O'Brien B, Stoddart G. Methods for the economic evaluation of health care programmes. Oxford, UK: Oxford University Press; 2005.

[64] Reda AA, Kotz D, Evers SM, van Schayck CP. Healthcare financing systems for increasing the use of tobacco dependence treatment. Cochrane Database Syst Rev 2012;6:CD004305.

[65] Stapleton JA, West R. A direct method and ICER tables for the estimation of the cost-effectiveness of smoking cessation interventions in general populations: application to a new cytisine trial and other examples. Nicotine Tob Res 2012;14(4):463-71.

[66] Caponnetto P, Polosa R. Common predictors of smoking cessation in clinical practice. Respir Med 2008;102(8):1182-92.

[67] West R, Ussher M. Is the ten-item Questionnaire of Smoking Urges (QSUbrief) more sensitive to abstinence than shorter craving measures? Psychopharmacology (Berl) 2010;208(3):427-32.

[68] Vangeli E, Stapleton J, Smit ES, Borland R, West R. Predictors of attempts to stop smoking and their success in adult general population samples: a systematic review. Addiction 2011;106(12):2110-21.

[69] Cosci F, Corlando A, Fornai E, Pistelli F, Paoletti P, Carrozzi L. Nicotine dependence, psychological distress and personality traits as possible predictors of smoking cessation. Results of a double-blind study with nicotine patch. Addict Behav 2009;34(1):28-35.

[70] Kotz D, West R. Explaining the social gradient in smoking cessation: it's not in the trying, but in the succeeding. Tob Control 2009;18(1):43-6.

[71] Rose JE, Behm FM. Adapting smoking cessation treatment according to initial response to precessation nicotine patch. Am J Psychiatry 2013; 170(8):860-7.

[72] Etter JF, Duc TV, Perneger TV. Validity of the Fagerstrom test for nicotine dependence and of the Heaviness of Smoking Index among relatively light smokers. Addiction 1999;94(2):269-81.

[73] Fidler JA, Shahab L, West R. Strength of urges to smoke as a measure of severity of cigarette dependence: comparison with the Fagerstrom Test for Nicotine Dependence and its components. Addiction 2011;106(3): 631-8.

[74] Mudde A, Willemsen M, Kremers S, De Vries H. Meetinstrumenten voor onderzoek naar stoppen met roken (Measurements for research on smoking cessation). The Hague: Stivoro; 2000.

[75] Cappelleri JC, Bushmakin AG, Baker CL, Merikle E, Olufade AO, Gilbert DG. Confirmatory factor analyses and reliability of the modified cigarette evaluation questionnaire. Addict Behav 2007;32(5):912-23.

[76] Pomerleau OF, Fagerstrom KO, Marks JL, Tate JC, Pomerleau CS. Development and validation of a self-rating scale for positive- and negative-reinforcement smoking: The Michigan Nicotine Reinforcement Questionnaire. Nicotine Tob Res 2003;5(5):711-8.

[77] Boudrez H, De Bacquer D. A Dutch version of the modified reasons for smoking scale: factorial structure, reliability and validity. J Eval Clin Pract 2012;18(4):799-806.

[78] Kotz D, Wesseling G, Huibers MJ, van Schayck OC. Efficacy of confrontational counselling for smoking cessation in smokers with previously undiagnosed mild to moderate airflow limitation: study protocol of a randomized controlled trial. BMC Public Health 2007; 7:332

[79] Curry S, Wagner EH, Grothaus LC. Intrinsic and extrinsic motivation for smoking cessation. J Consult Clin Psychol 1990;58(3):310-6.

[80] Georgiou A, Bradley C. The development of a smoking-specific locus of control scale. Psychol Health 1992;6:227-46.

[81] Cappelleri JC, Bushmakin AG, Baker CL, Merikle E, Olufade AO, Gilbert DG. Revealing the multidimensional framework of the Minnesota nicotine withdrawal scale. Curr Med Res Opin 2005;21(5):749-60.

[82] West R, Ussher M, Evans M, Rashid M. Assessing DSM-IV nicotine withdrawal symptoms: a comparison and evaluation of five different scales. Psychopharmacology (Berl) 2006;184(3-4):619-27. 
[83] Toll BA, O'Malley SS, McKee SA, Salovey P, Krishnan-Sarin S. Confirmatory factor analysis of the Minnesota Nicotine Withdrawal Scale. Psychol Addict Behav 2007;21(2):216-25.

[84] Busseri MA, Tyler JD. Interchangeability of the working alliance inventory and working alliance inventory, short form. Psychol Assess 2003;15(2): 193-7.

[85] Fucito LM, Toll BA, Salovey P, O'Malley SS. Beliefs and attitudes about bupropion: implications for medication adherence and smoking cessation treatment. Psychol Addict Behav 2009;23(2):373-9.

[86] Devilly GJ, Borkovec TD. Psychometric properties of the credibility/ expectancy questionnaire. J Behav Ther Exp Psychiatry 2000;31(2): 73-86.

[87] Zigmond AS, Snaith RP. The hospital anxiety and depression scale. Acta Psychiatr Scand 1983;67(6):361-70.

[88] Bjelland I, Dahl AA, Haug TT, Neckelmann D. The validity of the Hospital Anxiety and Depression Scale. An updated literature review. J Psychosom Res 2002;52(2):69-77.

[89] Terluin B, Brouwers EP, van Marwijk HW, Verhaak PF, van der Horst HE. Detecting depressive and anxiety disorders in distressed patients in primary care; comparative diagnostic accuracy of the Four-Dimensional Symptom Questionnaire (4DSQ) and the Hospital Anxiety and Depression Scale (HADS). BMC Fam Pract 2009;10:58

[90] Kotz D, Wesseling G, Huibers MJ, van Schayck OC. Efficacy of confronting smokers with airflow limitation for smoking cessation. Eur Respir J 2009 33(4):754-62.

[91] Campbell MK, Mollison J, Steen N, Grimshaw JM, Eccles M. Analysis of cluster randomized trials in primary care: a practical approach. Fam Pract 2000;17(2):192-6.

[92] White IR, Carpenter J, Horton NJ. Including all individuals is not enough: lessons for intention-to-treat analysis. Clin Trials 2012;9(4):396-407.

[93] Kahan BC, Morris TP. Reporting and analysis of trials using stratified randomisation in leading medical journals: review and reanalysis. BM] 2012;345:e5840.
[94] Kahan BC, Morris TP. Improper analysis of trials randomised using stratified blocks or minimisation. Stat Med 2012;31(4):328-40.

[95] Doll R, Peto R, Boreham J, Sutherland I. Mortality in relation to smoking: 50 years' observations on male British doctors. BMJ 2004;328(7455): 1519.

[96] Donders AR, van der Heijden GJ, Stijnen T, Moons KG. Review: a gentle introduction to imputation of missing values. J Clin Epidemiol 2006; 59(10):1087-91.

[97] Baron RM, Kenny DA. The moderator-mediator variable distinction in social psychological research: conceptual, strategic, and statistical considerations. J Pers Soc Psychol 1986;51(6):1173-82.

[98] Brookes ST, Whitely E, Egger M, Smith GD, Mulheran PA, Peters TJ. Subgroup analyses in randomized trials: risks of subgroup-specific analyses; power and sample size for the interaction test. J Clin Epidemiol 2004;57(3):229-36.

[99] Buczkowski K, Marcinowicz L, Czachowski S, Piszczek E, Sowinska A. What kind of general practitioner do I need for smoking cessation? Results from a qualitative study in Poland. BMC Fam Pract 2013;14:159.

[100] van Rossem C, Spigt M, Kleijsen JRC, Hendricx M, van Schayck CP, Kotz D. Smoking cessation in primary care: exploration of barriers and solutions in current daily practice from the perspective of smokers and healthcare professionals. Eur J Gen Pract 2015:1-7 [Epub ahead of print].

[101] Thorpe KE, Zwarenstein M, Oxman AD, Treweek S, Furberg CD, Altman DG, et al. A pragmatic-explanatory continuum indicator summary (PRECIS): a tool to help trial designers. J Clin Epidemiol 2009;62(5): 464-75.

[102] Nagelhout GE, de Korte-de Boer D, Kunst AE, van der Meer RM, de Vries $\mathrm{H}$, van Gelder BM, et al. Trends in socioeconomic inequalities in smoking prevalence, consumption, initiation, and cessation between 2001 and 2008 in the Netherlands. Findings from a national population survey. BMC Public Health 2012;12:303. 